\title{
Evaluation of Neurotoxicity in Lithium Treated Patients Admitted to Poison Control Center-Ain Shams University Hospitals during the Years (2011-2014)
}

\author{
Aya S. Khater and Nesrine M. Sarhan ${ }^{1}$
}

${ }^{1}$ Forensic Medicine and Clinical Toxicology Department, Faculty of Medicine, Ain Shams University, Cairo, Egypt.

\begin{abstract}
Lithium has been the first line drug in treating bipolar disorder. It has a low therapeutic index and toxic levels are frequently seen in clinical practice. Chronic lithium intoxication due to progressive accumulation of lithium was found to be more common. Symptoms are primarily neurologic; mental status is often altered and can progress to coma. The aim of the study is to evaluate the neurotoxicity among lithium intoxicated patients and its association with serum lithium levels through a cross sectional hospital based study over four years in the Poison Control Center, Ain Shams University Hospitals (PCC-ASUH). Factors affecting the outcome of lithium intoxicated patients were deduced.

Subjects and methods: Lithium intoxicated patients presented to the PCC-ASUH during the period from January 2011 to January 2015 were prospectively evaluated. For every patient we recorded the duration of lithium intake, comorbidities and concomitant use of medications. Clinical manifestations, serum lithium level, renal function (serum urea and creatinine) and serum electrolytes (sodium and potassium) in addition to the treatment characteristics were also recorded. Patients were divided according to their outcome into two groups: (Survivors and Non survivors).

Results: Twenty five lithium intoxicated patients were enrolled in our study; the mean duration of lithium therapy was similar in both groups (more than 12 years). The main clinical presenting sign of lithium intoxicated patients was coma with its different grades. Glasgow Coma Score (GCS) was significantly lower among non survivors. Relevant history of diabetes mellitus and hypertension was found in 15 patients and 13 patients respectively. Non psychotropic medications (including angiotensin converting enzyme inhibitors and diuretics) that interact with lithium clearance were more prevalent among non survivors. Neuroleptics were used by 22 patients and this was of no significant difference between survivors and non survivors. There was no significant difference between serum lithium levels in survivors and non survivors. Rehydration therapy with intravenous fluids was significantly more prevalent among the survivors. While no significant difference was found between both groups as regards the use of hemodialysis.

Conclusion: The serious morbidity suffered by lithium intoxicated patients might be reduced by careful monitoring and awareness of factors that might predict their outcomes including altered conscious level or drug interactions (diuretics or angiotensin converting enzyme inhibitors). Clinicians should seriously maintain a high level of suspicion in treating patients maintained on lithium noting that serum lithium levels do not accurately predict toxicity and they should not solely rely on it.
\end{abstract}

\section{Introduction}

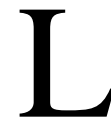
ithium is the most effective long-term therapy for bipolar disorder and is also effective in unipolar depression. However, there has been concern about its safety (Canadian Network for Mood and Anxiety Treatments (CANMAT), 2007). Lithium has a low therapeutic index. Toxic levels are frequently seen in clinical practice (Freeman and Freeman, 2006).

Three types of lithium intoxication are commonly presented; acute toxicity in patients not previously receiving lithium and occurs when the patient deliberately ingests large amounts of the drug in 
attempting suicide or overdoses accidentally, acute-ontherapeutic due to acute ingestion in the setting of current lithium treatment and chronic lithium toxicity (Waring et al., 2007). Chronic lithium intoxication was found to be the most common (Anderson et al., 2004). It occurs when there is progressive accumulation of lithium, usually due to renal dysfunction, drug interactions such as diuretics or angiotensin converting enzyme inhibitors, volume depletion, concurrent illnesses like congestive heart failure or cirrhosis all predispose a patient to chronic lithium toxicity (El Balkhi et al., 2009). Neurotoxicity is an important side effect of lithium therapy. It has been described both in lithium monotherapy with normal serum levels or with toxic levels, and in combined treatment with other therapeutics, particularly with antipsychotics or antidepressants (Boeker et al., 2011).

\section{The aim of the study}

Is to evaluate the neurotoxicity among lithium intoxicated patients and its association with serum lithium levels through a hospital based cross sectional study over four years in the Poison Control Center, Ain Shams University Hospitals (PCC-ASUH). Factors affecting the outcome of lithium intoxicated patients were deduced.

\section{Subjects and methods}

\section{Subjects}

Twenty five lithium intoxicated patients presented to the PCC-ASUH during the period from January 2011 to January 2015 were prospectively evaluated through a cross sectional hospital based study. The diagnosis of lithium intoxication was based on history of lithium intake, clinical manifestations of lithium toxicity and measuring serum lithium level.

\section{Exclusion criteria}

Pathological brain lesions documented by abnormal brain $\mathrm{CT}$ and/or MRI findings, patients with metabolic causes of disturbed level of consciousness and patients with neuroleptic malignant syndrome (excluded by absence of rigidity and normal total creatine kinase) were all excluded from the study.

Patients were divided according to their outcome into 2 groups, the first group: (Survivors) included 9 patients while the second group: (Non survivors) included 16 patients.

\section{Ethics}

Approval of the Ethical Committee and the Head of the PCC-ASUH were obtained. Informed written consents from the patients or their relatives were obtained. They were assured that any information they provided would be kept strictly confidential and anonymous.

\section{Methods}

I. Data collection: for every patient, the following data were recorded:

1. Demographic data: age, sex and occupation.

2. Intoxication data:

- Duration of lithium intake.

- Concomitant medications: (including neuroleptics or other medications)

3. Comorbidities: diabetes mellitus (DM), hypertension (HTN), heart disease and renal insufficiency.

4. Clinical manifestations: general and systemic examinations were performed on admission focusing on neurological examination; conscious level was evaluated by applying Glasgow Coma Score (GCS), reflexes and muscle tone.

5. Laboratory parameters ( the following parameters were measured on admission)

- Serum lithium level (Normal therapeutic range: $0.8-1.2 \mathrm{mEq} / \mathrm{L}$ ) (Severus et al., 2008).

- Renal functions: serum urea (Normal range: $10-50 \mathrm{mg} / \mathrm{dl}$ ) (Sue and Vintch, 2005) and serum creatinine: (Normal range: up to $1.4 \mathrm{mg} / \mathrm{dl}$ ) (Bazari, 2007).

- Serum electrolytes: serum sodium (Normal range: $135-150 \mathrm{mEq} / \mathrm{L}$ ) and serum potassium (Normal range: 3.5 $5.5 \mathrm{mEq} / \mathrm{L})$ (Faix, 2000).

6. Treatment: required treatment was done according to the protocol of management of lithium toxicity in the PCC-ASUH including intravenous fluid resuscitation and hemodialysis.

7. Follow up: patients were examined regularly for monitoring clinical conditions. The fate of patients (mortality or any complications) was recorded in a special sheet.

II. Statistical Analysis: The SPSS (Statistical Package for the Social Science) version 13, computer program was used. The outcome was the dependant factor, as the patients were divided into survivors and non survivors. Unpaired $\mathrm{t}$ test was used to compare the numerical data between both groups, while Chi- square test was used for the categorical data. $\mathrm{P}<0.05$ was considered significant. $\mathrm{P}<$ 0.001 was considered highly significant. 


\section{Results}

Twenty five cases were presented throughout the study period. They were all on lithium therapeutic doses; no acute deliberate toxicity was received. All cases presented with altered level of consciousness were admitted to the intensive care unit (ICU). Mortality occurred in 16 cases out of 25 with average duration of stay in ICU 16 days. Death was preceded by complications of prolonged coma. The clinical data records indicated that sex, age and duration of lithium therapy didn't influence the clinical course of lithium toxicity in the studied patients as shown in (Table 1 and Table 2).

\section{Analysis of associated medical conditions and drug interaction}

Positive medical history of diabetes or hypertension was found in 15 patients and 13 patients respectively, no significant differences between survivors and non survivors were found (Table 3). Neuroleptics were concomitantly used by 22 patients and were not statistically significant between survivors and non survivors Quetiapine and resperidone were the commonest drugs used by 6 patients for each.

Non psychotropic medications that interact with lithium clearance were more prevalent among non survivors and this was statistically significant. These drugs were angiotensin converting enzyme inhibitors (ACEIs) in 5 patients and diuretics in another 5 patients as shown in (Table 3 and Table 4).

\section{Clinical manifestations}

Fever was more prevalent among survivors, and this was statistically significant (Table 5).

All patients in the study presented with altered level of consciousness, Glasgow Coma Score (GCS) was significantly lower in non survivors (Table 6).

\section{Serum lithium level and other biochemical parameters}

There was no significant difference between serum lithium levels among survivors and non survivors. Urea to creatinine ratio was significantly higher in the survivors. Serum sodium was significantly higher in the survivors, while there was no significant difference between both groups as regards serum potassium level (Table 7).

\section{Treatment and outcome}

Table (8) shows that rehydration therapy with intravenous fluids was significantly present among survivors group. Hemodialysis didn't show the same efficacy as no statistical significant difference was found between both groups.

Among the survivors, persistent neurological sequels were found in 5 patients $(56 \%)$. They included persistent peripheral neuropathy in (1 patient), delirium (3 patients) and dysarthria (1 patient) (Table 9$)$.

Table (1): Fisher's exact test of sex distribution in lithium intoxicated patients admitted to PCC-ASUH (Survivors versus Non Survivors).

\begin{tabular}{|l|c|c|c|c|c|c|c|}
\hline \multirow{2}{*}{ Sex } & \multicolumn{2}{|c|}{$\begin{array}{c}\text { Survivors } \\
(\mathbf{N = 9 )}\end{array}$} & \multicolumn{2}{|l|}{ Non survivors (N=16) } & \multicolumn{2}{|c|}{ Total } & \multirow{2}{*}{ P-value } \\
\cline { 2 - 7 } & $\mathbf{N}$ & $\mathbf{\%}$ & $\mathbf{N}$ & $\mathbf{\%}$ & $\mathbf{N}$ & $\mathbf{\%}$ & \multirow{2}{*}{0.23} \\
\hline Female & 7 & 78 & 16 & 100 & 23 & 92 & \\
\hline Male & 2 & 22 & 0 & 0 & 2 & 8 & \\
\hline Total & 9 & 100 & 16 & 100 & 25 & 100 & \\
\hline
\end{tabular}

$P>0.05$ is considered insignificant, $N$ : number, \%: Percentage

Table (2): Student " $t$ " test comparing age and duration of therapy in lithium intoxicated patients admitted to PCCASUH among survivors and non survivors.

\begin{tabular}{|l|c|c|c|c|c|c|}
\hline \multirow{2}{*}{} & \multicolumn{2}{|c|}{ Survivors (N = 9) } & \multicolumn{2}{l|}{ Non survivors (N=16) } & \multicolumn{2}{l|}{ Independent t-test } \\
\cline { 2 - 8 } & $\begin{array}{c}\text { Mean } \pm \text { SD } \\
\text { (Years) }\end{array}$ & $\begin{array}{c}\text { Range } \\
\text { (Years) }\end{array}$ & $\begin{array}{c}\text { Mean } \pm \text { SD } \\
\text { (Years) }\end{array}$ & $\begin{array}{c}\text { Range } \\
\text { (Years) }\end{array}$ & t & P-value \\
\hline Age & $56.33 \pm 4.82$ & $49-63$ & $57.25 \pm 8.83$ & $40-66$ & 0.2866 & 0.7770 \\
\hline Duration of lithium therapy & $12.22 \pm 5.93$ & $3-22$ & $12.25 \pm 4.64$ & $5-20$ & 0.0130 & 0.9897 \\
\hline
\end{tabular}

$P>0.05$ is considered insignificant, $N$ : number 
Table (3): Fisher's exact test of the distribution of DM, hypertension and concomitant medications in lithium intoxicated patients admitted to PCC-ASUH (Survivors versus Non Survivors).

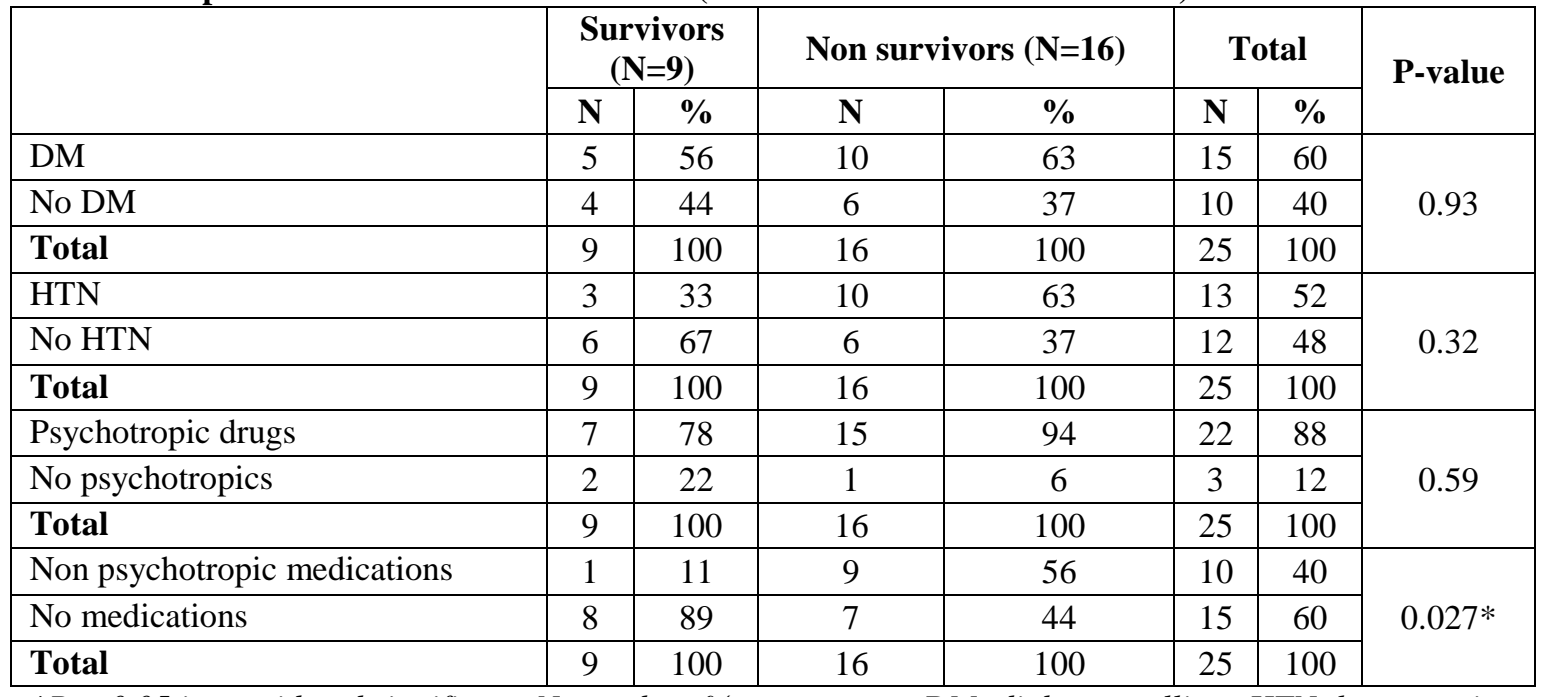

$* P<0.05$ is considered significant, $N:$ number, \%: percentage, DM: diabetes mellitus, HTN: hypertension

Table (4): Types of medications used concomitantly in lithium intoxicated patients admitted to PCC-ASUH (Survivors versus Non Survivors).

\begin{tabular}{|l|c|c|c|}
\hline Medications & Survivors & Non survivors & Grand Total \\
\hline Haloperidol & 0 & 2 & 2 \\
\hline Olanzapine & 1 & 2 & 3 \\
\hline Quetiapine & 4 & 2 & 6 \\
\hline Resperidone & 2 & 4 & 6 \\
\hline Valproate & 0 & 2 & 2 \\
\hline Venlafaxine & 0 & 3 & 3 \\
\hline ACEI & 1 & 4 & 5 \\
\hline Diuretics & 0 & 5 & 5 \\
\hline
\end{tabular}

ACEI: Angiotensin converting enzyme inhibitors

Table (5): Fisher's exact test of the distribution of fever in lithium intoxicated patients admitted to PCC-ASUH (Survivors versus Non Survivors).

\begin{tabular}{|l|c|c|c|c|c|c|c|}
\hline \multirow{2}{*}{ Fever } & \multicolumn{2}{|c|}{ Survivors $(\mathbf{N = 9})$} & \multicolumn{2}{|c|}{ Non survivors (N=16) } & \multicolumn{2}{|c|}{ Total } & \multirow{2}{*}{ P-value } \\
\cline { 2 - 7 } & $\mathbf{N}$ & $\mathbf{\%}$ & $\mathbf{N}$ & $\mathbf{\%}$ & $\mathbf{N}$ & $\mathbf{\%}$ & \\
\hline Fever & 5 & 56 & 0 & 0 & 5 & 20 & \\
\cline { 1 - 7 } No fever & 4 & 44 & 16 & 100 & 20 & 80 & \multirow{2}{*}{$0.004 *$} \\
\hline Total & 9 & 100 & 16 & 100 & 25 & 100 & \\
\hline
\end{tabular}

$* P<0.05$ is considered significant, $N$ : number, $\%$ : percentage

Table (6): Student " $t$ " test comparing Glasgow Coma Score in lithium intoxicated patients admitted to PCC-ASUH (Survivors versus Non Survivors).

\begin{tabular}{|c|c|c|c|c|c|c|}
\hline \multirow{2}{*}{} & \multicolumn{2}{|c|}{$\begin{array}{c}\text { Survivors } \\
(\mathbf{N}=\mathbf{9})\end{array}$} & \multicolumn{2}{c|}{$\begin{array}{c}\text { Non survivors } \\
(\mathbf{N}=\mathbf{1})\end{array}$} & \multicolumn{2}{c|}{ Independent t-test } \\
\cline { 2 - 7 } & Mean \pm SD & Range & Mean \pm SD & Range & T & p-value \\
\hline GCS & $9.22 \pm 0.83$ & $8-11$ & $8.00 \pm 1.03$ & $6-9$ & 3.0300 & $0.006 *$ \\
\hline
\end{tabular}

$* P<0.05$ is considered significant, GCS:Glasgow Coma Score, N: number 
Table (7): Student "t" test comparing laboratory data in lithium intoxicated patients admitted to PCC-ASUH (Survivors versus Non Survivors).

\begin{tabular}{|l|l|l|l|l|l|l|}
\hline \multirow{3}{*}{ Biochemical parameters } & \multicolumn{2}{c|}{$\begin{array}{c}\text { Survivors } \\
(\mathbf{N = 9 )}\end{array}$} & \multicolumn{2}{c|}{$\begin{array}{c}\text { Non survivors } \\
(\mathbf{N = 1}\end{array}$} & \multicolumn{2}{c|}{ Independent t-test } \\
\cline { 2 - 8 } & Mean \pm SD & Range & Mean \pm SD & Range & T & \multicolumn{1}{c|}{ P-value } \\
\hline Serum Lithium $(\mathrm{mEq} / \mathrm{L})$ & $2.36 \pm 1.28$ & $1.4-4$ & $2.5 \pm 0.79$ & $0.5-4$ & 0.41 & 0.682 \\
\hline Urea to creatinine ratio & $48 \pm 15.1$ & $69-33$ & $26.7 \pm 6.3$ & $14-38$ & 4.9 & $<0.0001^{*}$ \\
\hline Serum sodium $(\mathrm{Na})(\mathrm{mEq} / \mathrm{L})$ & $154.33 \pm 10.7$ & $134-163$ & $140.5 \pm 8.8$ & $126-152$ & 3.46 & $0.002 *$ \\
\hline Serum potassium $(\mathrm{K})(\mathrm{mEq} / \mathrm{L})$ & $3.6 \pm 0.6$ & $3-4.5$ & $3.56 \pm 0.59$ & $2.8-4.5$ & 0.04 & 0.871 \\
\hline
\end{tabular}

$* P<0.05$ is considered significant, $N:$ number

Table (8): Fisher's exact test of the distribution of treatment in lithium intoxicated patients admitted to PCC-ASUH (Survivors versus Non Survivors).

\begin{tabular}{|c|c|c|c|c|c|c|c|}
\hline \multirow{2}{*}{ Treatment modality } & \multicolumn{2}{|c|}{ Survivors $(n=9)$} & \multicolumn{2}{|c|}{ Non survivors $(n=16)$} & \multicolumn{2}{|c|}{ Total } & \multirow{2}{*}{ P-value } \\
\hline & $\mathbf{N}$ & $\%$ & $\mathbf{N}$ & $\%$ & $\mathbf{N}$ & $\%$ & \\
\hline Rehydration only & 5 & 56 & 0 & 0 & 5 & 20 & \multirow{3}{*}{$0.004 *$} \\
\hline No rehydration & 4 & 44 & 16 & 100 & 20 & 80 & \\
\hline Total & 9 & 100 & 16 & 100 & 25 & 100 & \\
\hline Hemodialysis & 4 & 44 & 5 & 31 & 9 & 36 & \multirow{3}{*}{0.82} \\
\hline Not dialyzed & 5 & 56 & 11 & 69 & 16 & 64 & \\
\hline Total & 9 & 100 & 16 & 100 & 25 & 100 & \\
\hline
\end{tabular}

Table (9): Distribution of persistent neurological sequels among the survivors of lithium intoxicated patients admitted to PCC-ASUH.

\begin{tabular}{|c|c|c|c|c|c|}
\hline \multicolumn{2}{|c|}{ No persistent sequels } & \multicolumn{2}{|c|}{ Persistent neurological sequels } & \multicolumn{2}{|c|}{ Grand Total } \\
\hline $\mathbf{N}$ & $\mathbf{\%}$ & $\mathbf{N}$ & $\mathbf{\%}$ & $\mathbf{N}$ & $\boldsymbol{\%}$ \\
\hline 4 & 44 & 5 & 56 & 9 & 100 \\
\hline
\end{tabular}

$N$ : number, \%: percentage

\section{Discussion}

In the current study, all patients were previously maintained on lithium therapy and no acute cases were presented during the study period. Similar results were obtained by (Oakley et al., 2001) who reported that severe lithium neurotoxicity occurs almost exclusively in the context of chronic therapeutic administration of lithium and rarely results from acute ingestion of lithium. As it is an iatrogenic illness, occurring in patients who have identifiable clinical risk factors; older age and impaired renal function.

Although the present study demonstrated the prevalence of lithium toxicity in females, yet we cannot consider sex as a risk factor as there was no significant difference between survivors and non survivors as regards the sex of patients. Similar findings were reported by Netto and Phutane (2012).On the other hand, (Lang and Davis, 2002\& Omata et al., 2003) in their studies considered female is a risk factor for developing lithium toxicity.

There was no significant difference in age between the survivors and the non survivors with mean age was above 55 years. This can be explained by altered pharmacokinetics, comorbid conditions, and concurrent medications. Lithium pharmacokinetics may be different in the elderly, as they have reduced volume of distribution and reduced renal clearance (Sproule et al., 2012).

As people increase in age, neurodegeneration, neurochemical and neurophysiologic changes occur in the brain that can sensitize it to lithium and lead to neurotoxicity at lower doses (Vaccari et al., 1997).

Co-morbid medical conditions such as heart disease, hypertension and renal insufficiency or brain disorders reported by Delva and Hawken (2001) may be risk factors for developing lithium intoxication. This may explain the high percentage of diabetes mellitus and hypertension in the patients under the current study. These diseases could have predisposed to occurrence of toxicity; however, they didn't affect the outcome of our patients.

Psychotropic drugs were common association in this study. Neuroleptics-lithium combinations were involved in precipitating lithium neurotoxicity as mentioned by Netto and Phutane (2012). Both typical and atypical antipsychotics such as haloperidol and risperidone were also co-administrated by some patients under the current study.

Miodownik et al., (2008) described a patient 
with delirium developed after adding lithium to ongoing quetiapine therapy, despite therapeutic doses of both medications and normal serum lithium levels. Boora et al., (2008) reported a patient developed encephalopathy within few days after starting the combination of lithium and risperidone. This finding was also supported by (Bender et al., 2004 and Lambreva et al., 2005).

This synergistic effect of lithium and antipsychotics can be explained by the effect of lithium on dopaminergic system, as lithium attenuates this dopaminergic system. It is assumed that dopamine release in the nucleus accumbens is reduced in subjects treated chronically with lithium and this effect may be maintained for three days after withdrawal of lithium therapy (Ferrie et al., 2008). In addition, antipsychotic drugs may increase lithium input to red blood cells thus leading to an increase in erythrocyte lithium concentration and neurotoxicity (Gille et al., 1997).

The present study shows that co-administration of some medications other than antipsychotics may be a risk factor in lithium intoxicated patients. They are mainly drugs affecting lithium clearance; particularly angiotensin converting enzyme inhibitors (ACEIs) and diuretics and were more prevalent in the non survivors. This agrees with the findings of Delva and Hawken (2001), Chen et al., (2004) and Yip and Yeung (2007). Oakley et al., (2001) concluded administration of drugs which impair lithium clearance appeared to 'uncover' the predisposing risk factors.

Lithium is a simple cation that is subjected to negligible protein binding, and is cleared almost exclusively by renal excretion. Around $80 \%$ of lithium filtered by the glomerulus is reabsorbed at the proximal convoluted tubule and to lesser extent, at the ascending limb of the loop of Henle and collecting ducts. Renal clearance of lithium is around 25-35 $\mathrm{ml} / \mathrm{min}$, representing around one-quarter of the glomerular filtration rate. Any medication or condition that alter the glomerular filtration rates (as ACEI, diuretics, advanced age, or volume depletion) or affects electrolyte exchange in the nephron may influence the pharmacokinetic disposition of lithium. (Timmer and Sands 1999).

Fever was more prevalent among survivors and was associated with the presence of a correctable precipitating factor, which was dehydration which was confirmed by low central venous pressure in these 5 cases. Dehydration was treated and after normalization of the central venous pressure, patients were improved spontaneously without performing hemodialysis. Dehydration decrease blood flow in the skin and decrease the sweat rate so consequently increase risk of hyperthermia (Bardis et al., 2013).

Glasgow Coma Score (GCS) was significantly lower in non survivors, indicating profound toxicity.

Features of lithium toxicity characteristically include drowsiness, slurred speech, psychomotor slowing, polyneuropathy, impaired memory and in severe cases; seizures, coma and death (Bartha et al., 2002).
Adityanjee et al., (2005) explained that lithium intoxication causes an encephalopathy with altered mental state, cerebellar dysfunction, seizures and rigidity. Netto and Phutane (2012) stated that delirium was the commonest manifestation of lithium toxicity.

Lithium has a unique pharmacokinetic property as it is absorbed from the upper gastrointestinal tract in approximately 8 hours, with peak serum level at 1-2 hours after oral administration. The permeability of the blood brain barrier for lithium is less than that of other tissues of the body and its distribution in the brain is delayed by approximately 24 hours as compared with that in the plasma (Finley et al., 1995). Consequently, patients with acute lithium intoxication may be presented with very high serum levels without apparent manifestations, on the other hand, they can be found in patients with chronic intoxication who have enough time to develop them. Therefore, neurological toxicity may develop with moderately elevated serum lithium levels or even normal therapeutic levels (Colvard et al., 2013).

In the current study, there was no significant difference between serum lithium levels in survivors and non survivors. Serum lithium concentrations did not predict outcome or clinical features. This agrees with Waring et al., (2007) who stated that pattern of lithium exposure appears to be a stronger indicator of severe toxicity rather than serum lithium level alone. Moreover in the current study, 4 patients in the non survivor group had serum lithium level within the therapeutic range. Similar findings were found by Megarbane et al., (2014) and Peng (2014).

This suggests that blood levels do not parallel intracellular level. The blood brain barrier displays a meager permeability for lithium, delaying lithium penetration into the brain for 24 hours. Since effects of lithium depend on the concentration of the drug on target organs, in acute intoxication, the initial rise in serum level can be seen in the absence of neurological symptoms. In chronic use, high intracellular lithium concentration in brain cells can occur, even with normal serum levels. Therefore, patients with chronic therapy are more susceptible to neurologic adverse effects (Chen et al., 2004). Moreover, Hillert et al. (2012) showed that lithium accumulates in the brain, especially with chronic treatment.

In a study by Forester et al. (2009) brain lithium levels did not correlate with serum lithium levels in those older than 50 years, in whom, elevations in brain (but not serum) lithium levels were associated with frontal lobe dysfunction. Notably the mean age in the current study was also above 50 years.

Some authors suggested that lithium concentration of red blood cells may better predict toxicity than serum lithium levels, particularly if toxicity occurs at therapeutic serum levels (Bell et al., 1993). However, Megarbane et al., (2014) and El Balkhi et al. (2009) in their studies reported inter- and intra-individual variability of these measures in their studies, depriving 
lithium concentration of red blood cells of any advantage over serum lithium level.

In this study, both urea to creatinine ratio and serum sodium level were significantly higher among the survivors. This confirms that dehydration was the precipitating cause for lithium toxicity in those patients, as increase urea to creatinine ratio is caused by hypovolemia that was confirmed clinically by decreased central venous pressure and urine output (Feinfeld and Harbord, 2010). Renal elimination is the only mean of eliminating lithium, any impairment of renal function, such as volume depletion, can precipitate lithium toxicity, especially in the long term use (Anderson et al., 2004). Increased renal tubular reabsorption of sodium, as in dehydration or decreased sodium intake may lead to lithium toxicity (Yip and Yeung, 2007).

Rehydration therapy with intravenous fluids in the current study was significantly more prevalent in the survivors, as the precipitating cause in this group was volume depletion. In the current study, there was no significant difference between both groups as regards the use of hemodialysis. This is expected as the decision of hemodialysis was based on the serum lithium level not the clinical severity of the setting. Oakley et al., (2001) noted this as a deficient guidance. Chen et al., (2004) found that most of their patients recovered spontaneously upon discontinuation of lithium, without hemodialysis, questioning the role of hemodialysis and how it should be determined.

Persistent neurological sequels in the form of persistent peripheral neuropathy, delirium and dysarthria were reported in the current study. Similar findings were recorded by Bartha et al. (2002), as they found persistent neurological sequels after recovery from the acute effects.

\section{Conclusion}

Lithium toxicity occurred mainly in patient on lithium therapy and was manifested by neurological manifestations in the form of different grades of altered conscious level. Administration of diuretics or ACEI with lithium therapy was found to be risk factors for bad prognosis. Age, concomitant DM or hypertension may predispose to lithium toxicity; however they didn't correlate with the outcome of patients. Lithium neurotoxic manifestations and mortality didn't correlate with serum lithium levels. Maintaining the hydration of the patients and discontinuation of lithium therapy were more significant in the outcome of patients than hemodialysis.

\section{Recommendations}

Further studies are needed to elicit the exact role of hemodialysis in outcome of lithium intoxicated patients and to set criteria for its indication other than lithium level. The study worth's to be extended on larger number of patients in different centers for elucidation of risk factors affecting the prognosis of lithium toxicity.

Careful attention of the physicians and closer monitoring of the patients on lithium therapy are very important to avoid concomitant drug use that may precipitate lithium toxicity and to pick up early neurological manifestation. Follow up central venous pressure and care of rehydration therapy are required. Although lithium level had little role in predicting the risk of toxicity, however it is still recommended to measure until it is proved to be useless on larger scales of studies.

The limitation was the relatively small size sample and only patients admitted to the PCC-ASUH were studied.

\section{References}

Adityanjee, Munshi KR, and Thampy A. (2005): The Syndrome of Irreversible Lithium-Effectuated Neurotoxicity. Clin. Neuropharmacol. 28(1): 3849.

Anderson IM, Haddad PM and Chaudhry I (2004): Changes in pharmacological treatment for bipolar disorder over time in Manchester. J. Psychopharmacol.18: 441 -4.

Bardis CN, Kavouras SA, Amaoutis G et al., (2013): Mild dehydration and cycling performance during hill climbing. J. Athl. Train. 48(6):741-7.

Bartha L, Marksteiner J, Bauer G, and Benke T (2002): Persistent cognitive deficits associated with lithium intoxication: A neuropsychological case description. Cortex 38:743-52.

Bazari H (2007): Approach to the patient with renal disease. In: Cecil Medicine, $23^{\text {rd }}$ edition, Goldman L and Aussiello D (editors), Saunders Elsevier. Philadelphia; pp: 1720-79.

Bell AJ, Cole A, Eccleston D et al., (1993): Lithium neurotoxicity at normal therapeutic levels. Br. J. Psychiat. 162: 689-92.

Bender S, Linka T, Wolstein J et al., (2004): Safety and efficacy of combined clozapine-lithium pharmacotherapy. Int. J. Neuropsychopharmacol.7 (1):59-63.

Boeker H, Seidl A, and Schopper C (2011): Neurotoxicity related to combined treatment with lithium, antidepressants and atypical antipsychotics. Schweizer Archiv. Neurol. Psychiat.162 (2):72-6.

Boora K, Xu J, and Hyatt J (2008): Encephalopathy with combined lithium-risperidone administration. Acta. Psychiatrica. Scandinavica. 117: 394-5.

Canadian Network for Mood and Anxiety Treatments (CANMAT) (2007): Guidelines for the management of patients with bipolar disorder: Update. Bipolar Disorder 8:721-39.

Chen KP, Shen WW, and Lu ML (2004): Implication of serum concentration monitoring in patients with 
lithium intoxication. Psychiat. Clin. Neurosci. 58: $25-29$.

Colvard MD, Gentry JD, and Mullis DM (2013): Neurotoxicity with Combined Use of Lithium and Haloperidol Decanoate. Prim. Care. Companion. CNS. Disord. 15 (6).

Delva NJ, and Hawken ER (2001): Preventing lithium intoxication. Can. Fam. Physician.47:1595-600.

El Balkhi S, Megarbane B, Poupon J et al., (2009): Lithium poisoning: Is determination of the red blood cell lithium concentration useful? Clin. Toxicol. 47(1): 8-13.

Faix JD (2000): In: Interpretation of Diagnostic Tests; $7^{\text {th }}$ edition; Wallach J (editor), Lippincott Williams and Wilkins. Philadelphia; pp: 1026.

Feinfeld DA and Harbord NB (2010): Renal principles. In: Goldfrank LR, Flomenbaum NE, and Lewis NA (eds): Goldfrank's Toxicologic Emergencies, 9th edition. New York, McGrawHill, pp: 387.

Ferrie LJ, Gartside SE, Martin KM et al., (2008): Effect of chronic lithium treatment on D2/3 autoreceptor regulation of dopaminergic function in the rat. Pharmacol. Biochem. Behav. 90(2):218-25.

Finley PR, Warner MD and Peabody CA (1995): Clinical relevance of drug interactions with lithium. Clin. Pharmacokinet. 29: 172-91.

Forester BP, Streeter CC, Berlow YA et al., (2009): Brain Lithium Levels and Effects on Cognition and Mood in Geriatric Bipolar Disorder: A Lithium-7 Magnetic Resonance Spectroscopy Study. Am. J. Geriatr. Psychiat.17 (1): 13-23.

Freeman MP and Freeman SA (2006): Lithium: Clinical considerations in internal medicine. Am. J. Med.119:478-81.

Gille M, Ghariani S, Pieret F et al., (1997): Acute encephalomyopathy and persistent cerebellar syndrome after lithium salt and haloperidol poisoning. Rev Neurol;153: 268-70.

Hillert M, Zimmermann M and Klein J (2012): Uptake of lithium into rat brain after acute and chronic administration. Neurosci. Lett. 521(1): 62-66.

Lambreva E, Vecellio M, Wieser HG et al., (2005): Neurotoxische Enzephalopathie unter Neuroleptika und Lithium. Nervenarzt; 76:7569.

Lang EJ and Davis SM (2002): Lithium neurotoxicity: The development of irreversible neurological impairment despite standard monitoring of serum lithium levels. J. Clin. Neurosci. 9:308-9.
Megarbane B, Hanak AS, and Chevillard L (2014): Lithium-related neurotoxicity despite serum concentrations in the therapeutic range: risk factors and diagnosis. Shanghai. Arch. Psychiat. 26(4): 243-4.

Miodownik C, Alkatnany A, Frolova K et al., (2008): Delirium associated with Lithium-Quetiapine Combination. Clin. Neuropharmacol. 31(3):176-9.

Netto I and Phutane VH (2012): Reversible Lithium Neurotoxicity: Review of the Literature. Prim. Care Companion CNS Disord. 14 (1).

Oakley P W, Whyte I M and Carter G L (2001): Lithium toxicity: An iatrogenic problem in susceptible individuals. Australian and New Zealand J. Psychiat. 35: 833-80.

Omata N, Murata T, Omori M and Wada Y (2003): A patient with lithium intoxication developing at therapeutic serum lithium levels and persistent delirium after discontinuation of its administration. Gen. Hosp. Psychiat. 25:53-5.

Peng J (2014): Case report on lithium intoxication with normal lithium levels. Shanghai. Arch. Psychiat. 26(2): 103-4.

Severus WE, Kleindienst N, Seemüller F et al., (2008): What is the optimal serum lithium level in the long-term treatment of bipolar disorder--a review? Bipolar Disord. 10 (2):231-7.

Sproule BA, Hardy BG, and Shulman KI (2012): Differential pharmacokinetics of lithium in elderly patients. Drugs \& Aging. 16:165-77.

Sue D and Vintch J (2005): Fluids, electrolytes and acid base. In: Current Essentials of Critical Care, Sue $\mathrm{D}$ and Vintch $\mathrm{J}$ (editors). Lang Medical Books, London; pp: 51-69.

Timmer RT and Sands JM (1999): Lithium intoxication. J. Am. Soc. Nephrol. 10: 666-74.

Vaccari A, Saba PL, Mocci I, et al., (1997): Is increased neurotoxicity a burden of the ageing brain? In: Freund HJ, Sabel BA, White OW, editors. Brain plasticity. Philadelphia, Pa: Lippincott-Raven; pp: 221-34.

Waring WS, Laing WJ, Good AM et al., (2007): Pattern of lithium exposure predicts poisoning severity: evaluation of referrals to a regional poisons unit. Q. J. Med.100: 271-6.

Yip KK and Yeung WT. (2007): Lithium overdose causing non-convulsive status epilepticus-the importance of lithium levels and the electroencephalography in diagnosis. Hong Kong Med. J.13:471-4. 
الملخص العربي

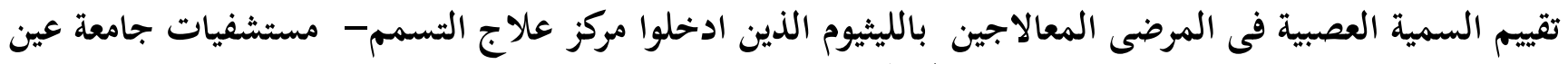

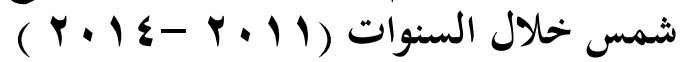

\section{آية شوقى خاطر و نسرين محمد سرحان 1}

يعد الليثيوم هو الخط الأول في علاج الاضطراب ثنائى القطبية. و له مؤشر علاجى منخفض ولهذا يصل كثيرا للمستويات السامة في الممارسة

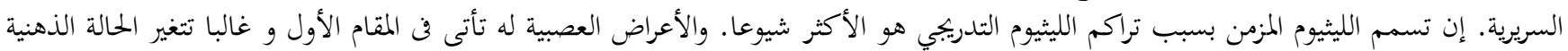
لتصل إلى الغيبوبة .

الهدف من الدراسة: تقييم السمية العصبية لدى مرضى الليثيوم وارتباطها بمستويات الليثيوم في الدم من خلاتلال دراسة مستعرضة على مدى

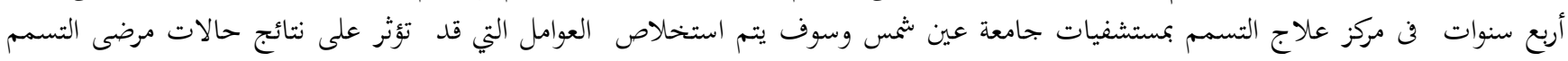
بالليثيوم.

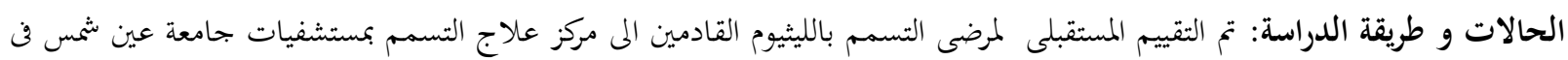

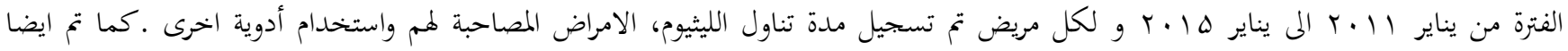
تسيجيل المظاهر السريرية و مستوى الليثوم بالدم ووظائف الكلى(يوريا و كرياتينين) مستوى الصوديوم والبوتاسيوم بالدم بلإضافة إلى تسجيل العلاج المتبع. و قد تم تقسيم المرضى وفقا للنتائج المى بجموعتين ( الناجين و والدم ووظائ النكي الناجين).

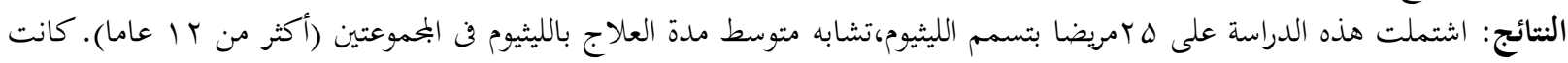

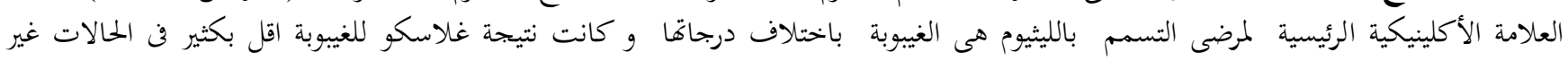

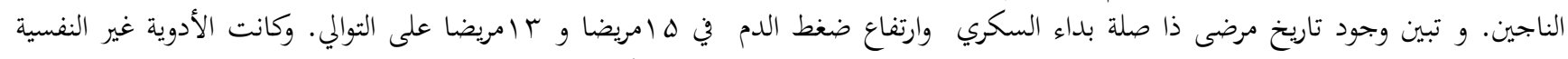

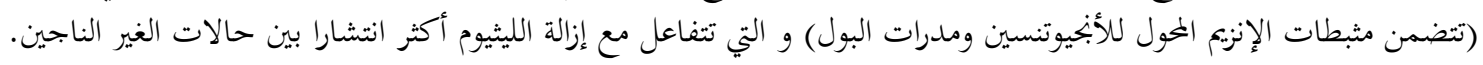

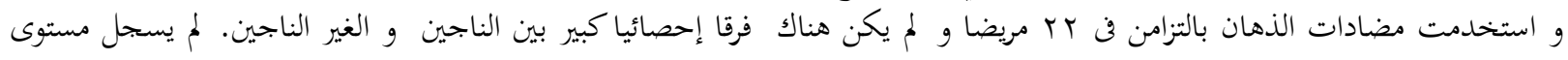

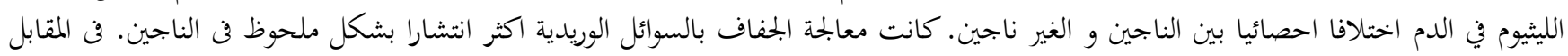

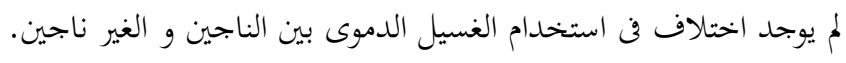

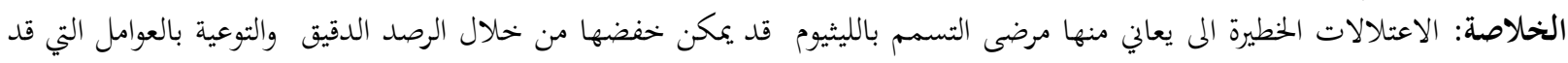

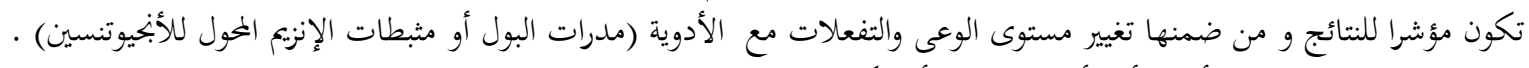

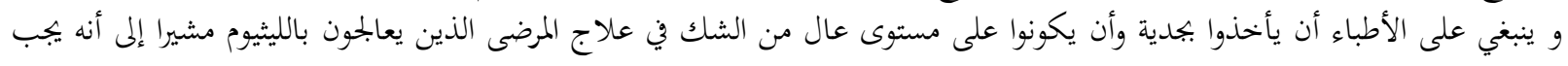

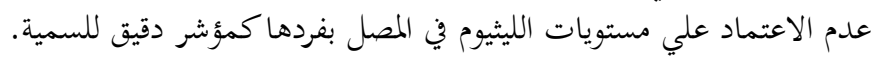

